\title{
Anthropocene climate and landscape change that increases flood disasters
}

\begin{abstract}
Global increase in flood frequency and magnitude are caused by anthropogenic activities. From 1980 to 2009, floods have resulted in more than 500,000 deaths and affected above 2.8 billion people worldwide based a national climate assessment. Thus, anthropogenic activities have presented great concerns toward regions affected by disastrous floods in the past. Determining possible human activities which have greatly influenced the magnitude and frequency of past flooding in developed and developing countries is the focus of this paper. Anthropogenic activities contribute to flooding through landscape modification and atmospheric changes. Implications of these findings should be included in policy decision making to address their impact on flooding to reduce flooding vulnerability. Landscape modification through urbanization, deforestation and large-scale agricultural practices promotes flooding in urban and rural areas. On the other hand, anthropogenic atmospheric changes have contributed to flood disasters. Industrialization in developing countries increases carbon emissions, activating the 'aerosol-enhanced conditional instability' mechanism. As a result of this, Sichuan experienced a catastrophic flooding in 2013. Also, rainfall levels in urban areas have risen due to the 'urban heat island' effect. In recent years, anthropogenic activities have played a crucial role in major flooding events and further research will help manage and mitigate flood risks.
\end{abstract}

Keywords: anthropogenic impacts, climate change, landscape change, increased floods
Volume 2 Issue 4 - 2018

\author{
Chua Li-An,' Lawal Billa,' Majid Azari'² \\ 'School of Environment and Geographical Sciences, University \\ of Nottingham, Malaysia \\ ${ }^{2}$ Department of Civil Engineering, University of Nottingham, \\ Malaysia
}

\begin{abstract}
Correspondence: Lawal Billa, School of Environment and Geographical Sciences, University of Nottingham, Malaysia,
\end{abstract} Email Lawal.Billa@nottingham.edu.my

Received: August 01, 2018 | Published: August 13, 2018

\section{Introduction}

Since the industrial revolution, unprecedented human activities have modified the environment to the extent that this era has been termed the "Anthropocene". Over the last 200 years, the development of newly introduced anthropogenic activities have played a major role in changing the dynamics of our world. ${ }^{2}$ These human activities have had various impacts on earth systems, such as the atmosphere, hydrology, biosphere and geosphere, by modifying earth system processes, interactions and landscapes. By modifying the landscape and atmosphere, anthropogenic activities lead to changes in hydrological characteristics which has exacerbated flooding in the world today. ${ }^{3}$ Human activities alter the landscape through urbanization, industrial development, changes in agricultural practices and intensity. Factors influencing flooding in urban and rural areas differ. Development of technology in this era encourages innovation of agricultural practices and expansion of industries which alter the composition of earth's atmosphere and natural landscape. The modification of climatic patterns by anthropogenic activities, such as industrialization, increases greenhouse gases concentration in the atmosphere. ${ }^{4}$ Global carbon dioxide, in particular, rose tremendously from 275 parts per million (ppm) to $380 \mathrm{ppm}$ between the year 1750 and $2000 .^{5} \mathrm{In}$ turn, this influences temporal and spatial variability in the isotopic composition of rainfall, enhancing inundation in an area.

A study by Bradshaw et al., ${ }^{6}$ looked at deforestation and its contribution to flooding. The study collected data from 1990 to 2000 from 56 developing countries around the world, and the results showed an increase of $4 \%-28 \%$ in flood frequency due to a $10 \%$ decrease in natural forest area, and a 4\%- $8 \%$ increase in total flood duration. Urbanization is one of the major contributors to flooding, where land use and land cover changes from natural land to urban areas leads to increases in flood occurrences. For example, in the Oshiwara river basin in Mumbai, Indian there was a $74.84 \%$ increase in urban area and a $42.8 \%$ decrease in open spaces between 1966 to 2009, which resulted in increased runoff and runoff volume with the 2 year return period having higher runoff than the 100 year return period. There was also an increase in areas at risk of flooding by $64.29 \% .^{7}$ Due to large populations and high number of infrastructure and properties in urban areas, there is more risk of loss of life and damage to property. For example, the expected annual damage caused by flooding in UK is $£ 1$ billion (Hall et al, 2005). In 2015 flooding had the largest number of events compared to other natural disaster, with 156 floods events taking place worldwide, which resulted in US\$ 21.3 billion in damages. ${ }^{8}$ Providing a background of the relationship between human activities and flooding, this paper is written to elaborate several common human-induced flooding affecting planet earth. An understanding of how anthropogenic activities lead to flooding will help aid effective policy-making at local, national and international levels to prevent and mitigate flooding risks in the future. In this paper, we will be focusing on the anthropogenic activities which contributed to past flood disasters in the world.

\section{Anthropogenic atmospheric changes}

\section{Changes in regional and global climate}

Industrialisation is the process of transforming an economy from a primary sector to a manufacturing sector. With the rise in the number of factories being built globally there is an increase in air pollution, resulting in more greenhouse gases being released in the atmosphere. By conducting simulations Fan et al., ${ }^{9}$ believed that air pollution 
emitted from factories in Sichuan had a direct effect on the rainfall and eventual flooding that took place in 2013, which killed approximately 200 people (Figure 1). The mechanism called aerosol-enhanced conditional instability occurs when industries burn fossil fuels or biomass, producing a pollutant called 'black carbon,' which is then suspended into the atmosphere to absorb the sun's radiation. ${ }^{9}$ During the daytime, this process stabilises the atmosphere and suppresses local storms. Subsequently, the wind transports heavy warm moist air to mountainous regions, which is lifted, increasing precipitation in the evening (Figure 2). ${ }^{9}$ Realised that the worst flooding occurred at the downwind of the Sichuan Basin, a valley covered with highly polluted air from industries. She explained that "the pollution transformed this mild rain over a very large area of the basin during the daytime into a heavy rain, focused on a narrow area over the mountains"
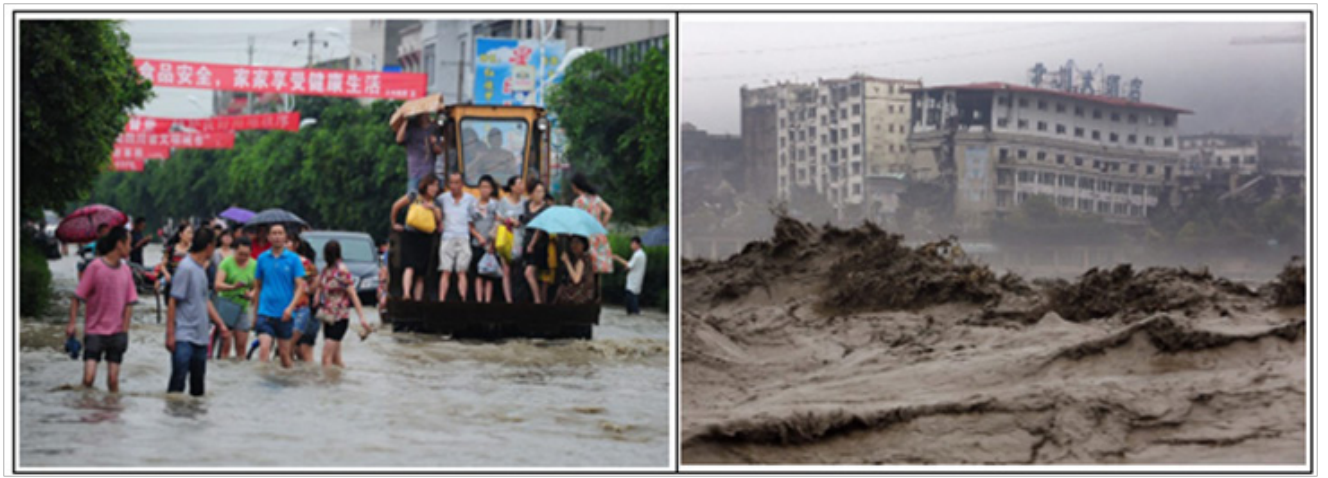

Figure I Effect of the 2013 Sichuan flood disaster. ${ }^{29}$

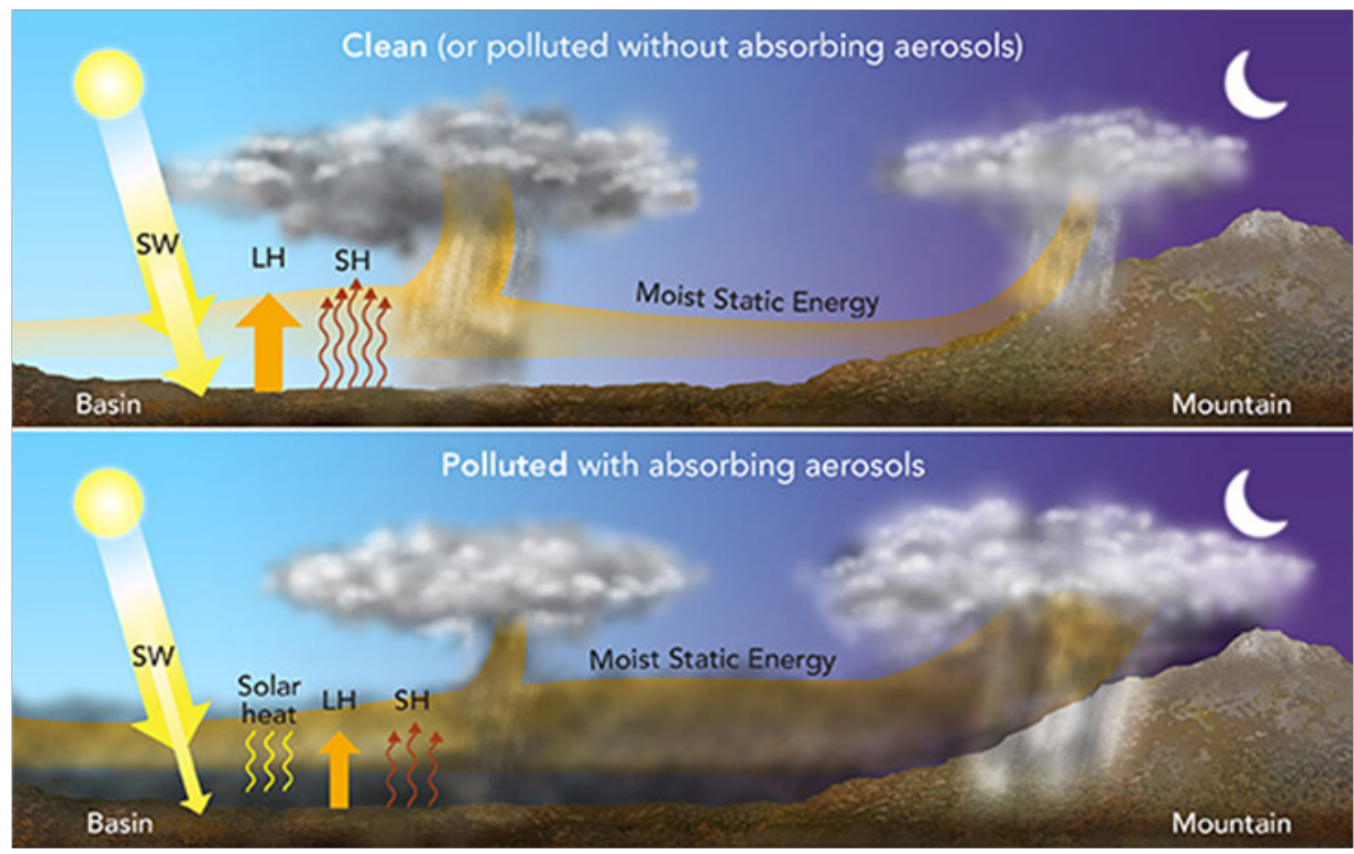

Figure 2 Aerosol-enhanced conditional instability increasing rainfall levels in Sichuan. Acronyms: MSE (moist static energy), SW (shortwave radiation), SH (surface sensible heat flux), and LH (surface latent heat flux). ${ }^{9}$

\section{Effect of urban heat island on microclimate}

Urban areas are often warmer than rural areas (Figure 3) this phenomenon is known as the 'urban heat island' effect. On average, urban areas are 1-2 degree Celsius warmer than neighboring rural areas due to anthropogenic activities. ${ }^{10}$ Tall buildings trap more heat in between them. Urban canyons, which is the narrow arrangement of buildings along streets, inhibits reflected radiation from escaping into space, reducing the sky view factor, which enhances the urban heat island effect. Also, concrete has a low albedo between 10-35\%, and this escalates surface temperature in cities. ${ }^{10}$ As temperature increases, air becomes unstable, causing it to rise up the atmosphere. Air cools as it rises, allowing water vapor within it to condense and form cumulonimbus clouds at the dew point, where latent heat is released. If air particles carry adequate water vapor, the clouds would transform into rain clouds, making cities more prone to thunderstorms, thus increasing the vulnerability of flooding in urban areas. In Northern Taiwan heat from anthropogenic activities influences precipitation formation, where climate modeling shows precipitation to be stronger on urban areas compared to non-urban areas. ${ }^{11}$ In another study by Yang et al., ${ }^{12}$ it was observed that there was a relationship between 
urban heat island intensity (UHII) and short duration intense rainfall (SDIR) in Beijing. The study found that SDIR occurred more frequently in urban areas compared to rural areas and mostly in the summer, it also showed that UHII was at its highest before the start of SDIR event.

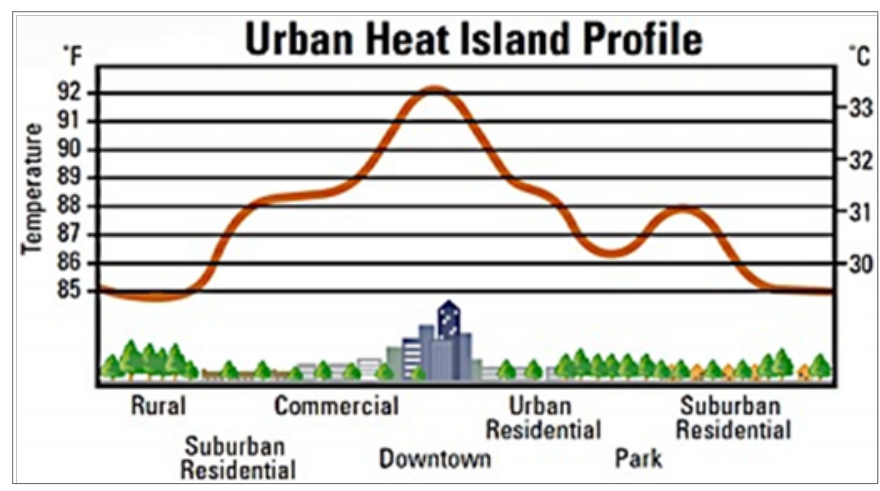

Figure 3 Urban heat island profile. ${ }^{30}$

\section{Landscape change and modification}

\section{Urbanization leading to a rise in surface runoff}

Economic growth and development have contributed to the increase in intraregional migration from rural to urban areas. 200 years ago, only $2 \%$ of the world's population lived in urban areas but recently, this percentage has risen to nearly $50 \% .^{13}$ As a result of rising urbanization, natural soil from the ground is replaced by impermeable surfaces, such as concrete, to create a foundation suitable for the development of new buildings and roads. ${ }^{14}$ As a consequence of this, infiltration rates would fall due to the lack of permeable rocks and vegetation which aids both percolation and absorption of incoming rainwater; surface runoff of rainwater in urban areas will rise, lowering the groundwater table. Increase in surface runoff also results in a smaller proportion of rainwater contributing to baseflow, evapotranspiration and groundwater recharge. Urbanization results in a steeper rising limb and recession limb in a flood hydrograph as seen in Figure 4. Lag time also decreases, thus increasing flood frequency. Based on Figure 5 below, the river's discharge and flood disasters occurrence increases as urbanisation takes place; in an 'unurbanised' area (for example, a rural area), flooding tends to occur every 0.5 to 10 years. However, in an area which has faced urbanisation, flooding is more likely to happen every 0.2 to 1.8 years with a larger impact, thus implying that the occurrence and magnitude of flooding in an urbanised area is greater. Modelling techniques have help in demonstrating the impact of urban surfaces on rainfall flows, for example Guan et al., ${ }^{15}$ used the Stormwater Management Model (SWMM) to find out how hydrological processes change in an urban area in southern Finland. The findings showed that flow rates increase with an increase in impervious surfaces, and areas contributing to runoff increased which resulted in volume of runoff to double. In a similar study in Jakarta, Indonesia Remondi et al. ${ }^{16}$ discovered that uncontrolled urbanization resulted in rise in flood events.

\section{Uncontrolled urbanization}

Uncontrolled urbanisation is often accompanied by poor infrastructure planning, especially in developing countries. Poor management of infrastructure, drains and irrigation canals reduces the flow carrying capacity of an urban drainage system, aggravating flash floods. Although Kuala Lumpur's drainage system was well-designed, a lack of maintenance and cleaning enabled the accumulation of silt, garbage and debris, reducing carrying capacity by 50 percent, thus increasing flooding vulnerability. ${ }^{17}$ Developing countries, in particular, lack sufficient resources to prevent flooding by improving drainage infrastructure to cope with population pressures. Flooding in Bangladesh has become a normal and frequent phenomenon due to poor drainage in cities, which increases the vulnerability of floods especially during raining seasons. ${ }^{18}$ In a normal year, the IPCC Special Report on Extreme Events (SREX) estimated that drainage congestion causes inundation of approximately $20-25 \%$ of Bangladesh area. ${ }^{19}$ On the other hand, poor planning and resource allocation can also affect the recurrence of flooding in well-resourced developed countries. A spate of flash floods in Singapore between 2010 and 2013 has been attributed to more intense rainfall, as well as development and population pressures exceeding the capability of existing drainage infrastructure to cope. ${ }^{20}$ Thus, even cities with adequate resources and a good track record of proactive urban planning can also fail to adapt to changing circumstances in a timely manner.
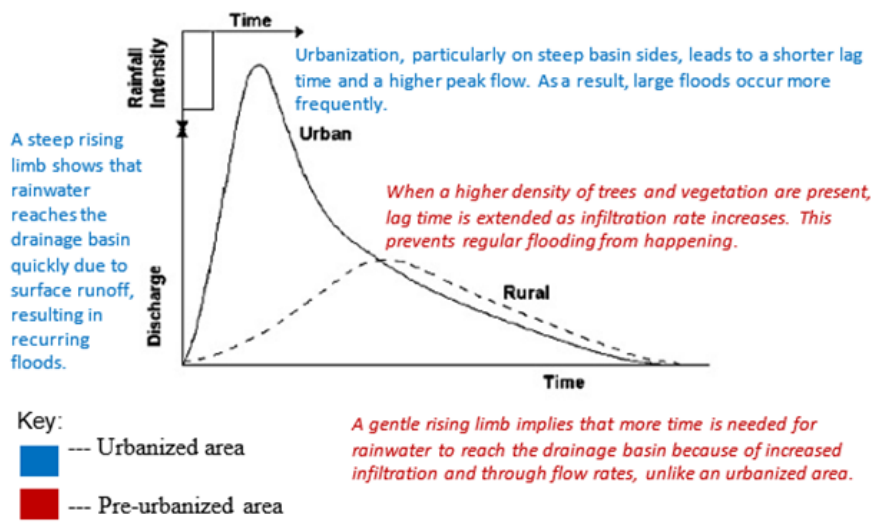

A gentle rising limb implies that more time is needed for rainwater to reach the drainage basin because of increased infiltration and through flow rates, unlike an urbanized area.

Figure 4 Flood hydrograph before and after urbanization: adapted from. ${ }^{31}$

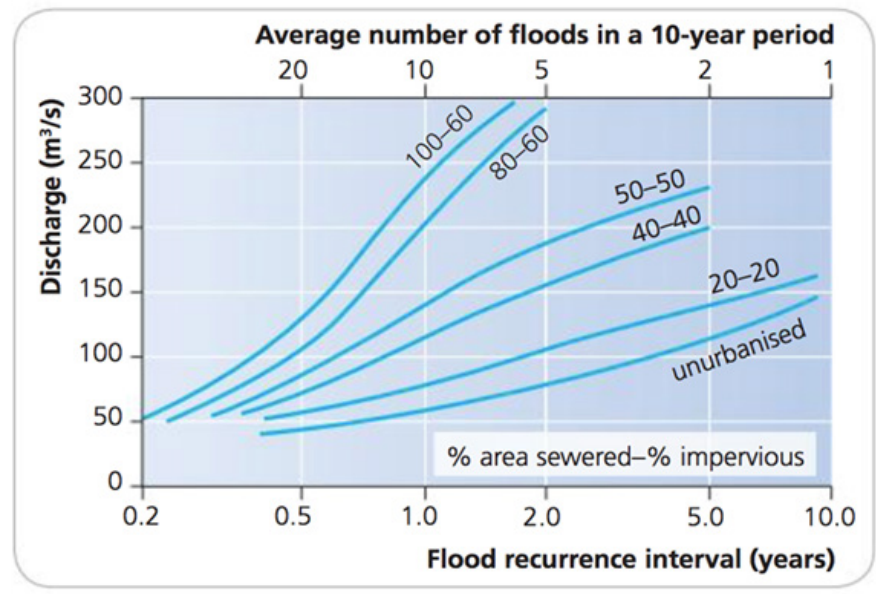

Figure 5 Urbanization and flood occurrence..$^{32}$

\section{Deforestation of upper catchment areas}

There is a link between deforestation, soil erosion and river sedimentation. Deforestation of upper catchment areas leads to soil erosion, reducing soil fertility, which inhibits the infiltration of rainwater. ${ }^{21}$ The absence of trees reduces evapotranspiration, affecting 
the latent heat flux, and interception rates would also fall. ${ }^{22}$ As a result, overland runoff of rainwater increases, and sediment deposition on river beds is enhanced. This results in major flooding in low-lying regions due to a fall in the river's capacity. More frequent flooding also occurs due to a shorter lag time (refer to Figure 1). The Upper Ganga catchment of the Central Himalaya is widely known to cause flooding in lower regions. Claims have suggested that deforestation of the Himalayas (Figure 6) has increased flooding of the Gangetic Plain in India and Bangladesh. ${ }^{23}$ In another study by Wiekenkamp et al., ${ }^{24}$ changes to hydrological components due to partial deforestation was measured in the upper Wustebach catchment in Germany. The study looked at data for 3 years before deforestation and 2 years after deforestation, and found there was a decrease in evapotranspiration and increase in discharge. Overall the decrease in evapotranspiration resulted in immense increase in soil water storage, hence increasing the frequency of high discharge.

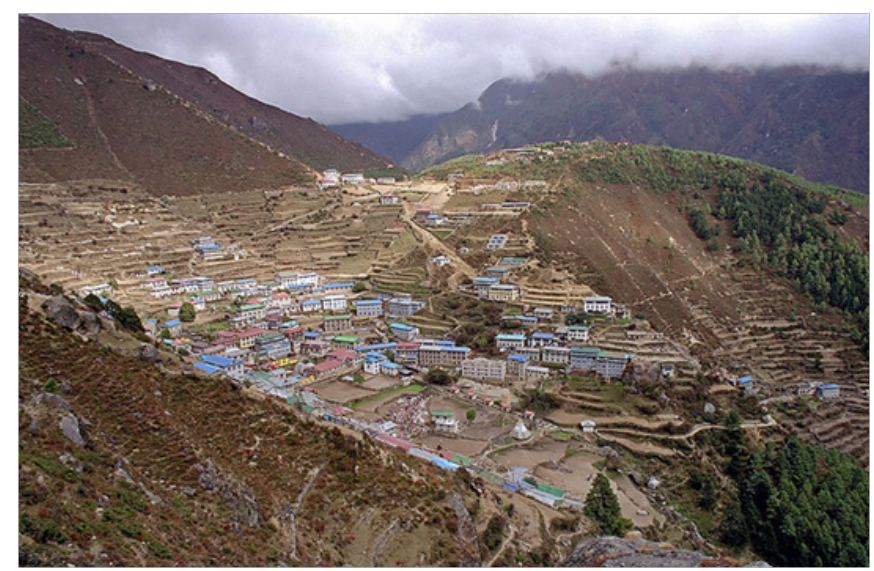

Figure 6 Deforestation of the Himalayas due to population pressure..$^{33}$

\section{Large-scale agricultural and forestry practices}

Over-cultivation, over-grazing and the slash-and-burn technique have triggered flooding. ${ }^{25}$ Over-cultivation involves a piece of land used for farming for a long period of time, causing soils to become so infertile till the point where no vegetation can grow on it. Overgrazing occurs when too many animals on land is grazed, causing pasture to be eaten away quickly due to inadequate recovery periods (Figure 5). This reduction of vegetation cover decreases infiltration rates. The slash-and-burn technique is a process where fire is set onto a patch of rainforest, clearing the area to make way for plantations. Initially, the ash aids soil fertility and the presence of weeds on the plot is relatively low. As time passes by, soil fertility falls and weeds grow, preventing the area from sustaining future vegetative growth. ${ }^{26}$ Figure 7 illustrates the relationship between overgrazing, over-cultivation, slash-and-burn technique and flooding. Furthermore, changes in agricultural practices have led to more deeply compacted soils, lines left from ploughing and cracks in soils. ${ }^{27}$ Factors, such as soil compaction, caused by the usage of heavy machinery, reduces its porosity, inhibiting the soil from storing more water which then reduces antecedent moisture. This in turn increases surface runoff of a greater volume of water, increasing the risk of flooding. Besides that, clearing a patch of rainforest to make space for new crops to be cultivated causes the exposed topsoil to be eroded by wind or rain Brazil has been shown to aggravate flooding due to soy production. ${ }^{28}$ This has not only caused land degradation but has led to the increase in debris and sedimentation flow, contributing to floods Figure $8 .{ }^{29}$

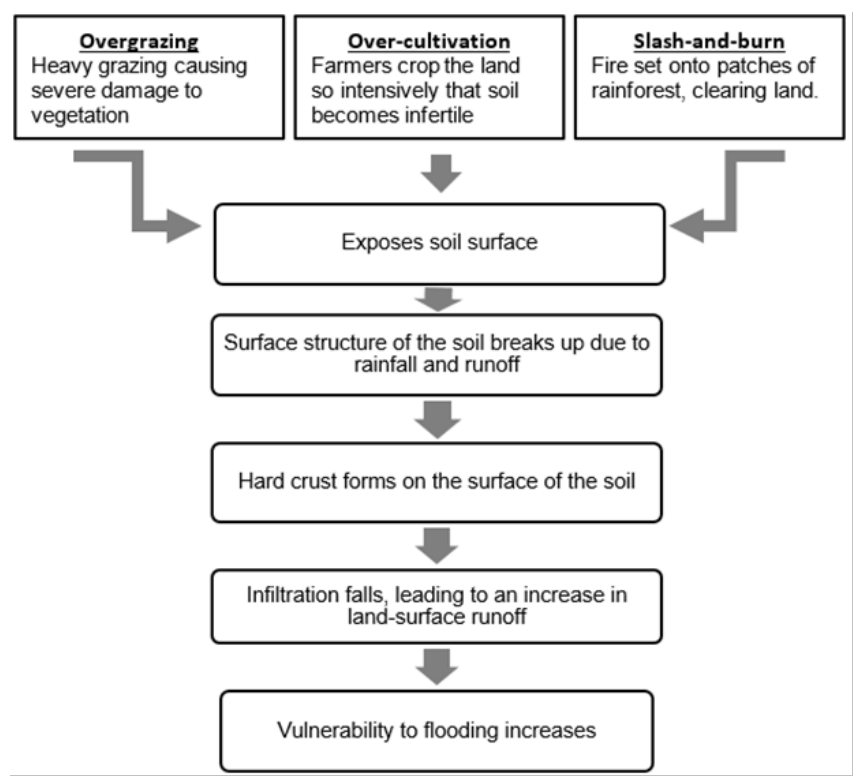

Figure 7 The link between overgrazing, over cultivation and the slash-andburn technique on flooding disasters. Modified from. ${ }^{34}$
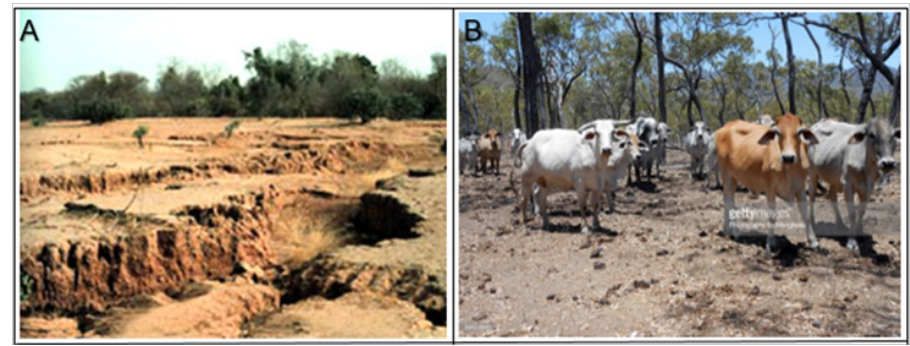

Figure 8 Overgrazing and over-cultivation reduces soil fertility, increasing flooding vulnerability. (A) Overcultivation in Sahel,West Africa (Source: USGS, EROS (year N/A)); (B) Overgrazing of cows in northern Australia (Source: gettyimages (year N/A)).

\section{Conclusion}

Flood disasters are becoming a global problem faced by many countries due to both human and physical activities. Coordinated action amongst different stakeholders at both global and local levels is necessary to reduce the vulnerability of developed and developing countries to flooding in the future. ${ }^{30}$ The earth system, consisting of the atmosphere, hydrosphere, biosphere and geosphere, interact with each other naturally; however, anthropogenic activities have disturbed and altered the processes, interactions and landscape of planet earth, contributing to flooding disasters in the world today. Urbanization particularly increases the magnitude and occurrence of flooding in countries facing great intraregional migration. Within this context, developing and developed countries around the world have been adversely affected by uncontrolled urbanization due to various factors; in developing countries, such as Bangladesh, lack of financial resources has inhibited the country from improving its drainage system to prevent further flooding events. On the other hand, Singapore, a developed country, faces flash floods due to poor urban planning and resource allocation. With the continuous development of urban areas, changes in microclimate have increased precipitation locally due to the urban heat island effect. Through the introduction 
of new agricultural techniques and technology advancements, farmers have developed new agricultural practices of growing crops, some of which have degraded the environment, indirectly triggering floods. In the long term, a persistent increase in sea levels and more intense weather patterns due to global warming is expected to worsen future floods. Despite the inevitability of such global warming effects, proactive implementation of flood prevention policies will go a long way towards managing flood-inducing anthropogenic activities to moderate potential flooding events..$^{31-36}$

\section{Acknowledgements}

None.

\section{Conflict of interest}

The author declares there is no conflict of interest.

\section{References}

1. National Cimate Assessment. Extreme Weather. 2014.

2. Dalby S. Rethinking Geopolitics: Climate Security in the Anthropocene. Global Policy. 2014;5(1):1-9.

3. Duaibe K. Human Activities and Flood Hazards and Risks in the South West Pacific: a Case Study of the Navua Catchment Area, Fiji Islands. Victoria University of Wellington. 2008.

4. Bouwer LM. Have disaster losses increased due to anthropogenic climate change? American Meteorological Society. 2011;91(1):39-46.

5. Solomon S, Qin D, Manning M, et al. How do Human Activities Contribute to Climate Change and How do They Compare with Natural Influences? Cambridge, United Kingdom and New York, NY, USA: Cambridge University Press. 2007;1-4.

6. Bradshaw CJA, Sodhi NS, Peh KSH, et al. Global evidence that deforestation amplifies flood risk and severity in the developing world. Global Change Biology. 2007;13:2379-2395.

7. Zope PE, Eldho TI, Jothiprakash V. Impacts of land use-land cover change and urbanization on flooding: A case study of Oshiwara River Basin in Mumbai, India. Catena. 2016;145:142-154.

8. Gupa-Sapir D, Hoyois P, Below R. Annual disaster statistical review 2015: The numbers and trends. CRED. 2016

9. Fan J, Rosenfeld D, Yang Y, et al. Substantial contribution of anthropogenic air pollution to catastrophic floods in Southwest China. Geophysical Research Letters. 2015;42(12):6066-6075.

10. Parsons G. Urban Microclimates. Geofile Online. 2003;457.

11. Lin CY, Chen WC, Chang PL, et al. Impact of the urban heat island effect on precipitation over a complex geographic environment in Northern Taiwan. American Meteorological Society. 2011;50:339-353.

12. Yang P, Ren G, Yan P. Evidence of a strong association of short-duration intense rainfall with urbanization in the Beijing urban area. American Meteorological Society. 2017;30:5851-5870.

13. Torrey B. Urbanization: An Environmental Force to Be Reckoned With. Population Reference Bureau. 2005.

14. Konrad C. Effects of Urban Development on Floods. US Geological Survey. 2016
15. Guan M, Sillanpää N, Koivusalo H. Modelling and assessment of hydrological changes in a developing urban catchment. Hydrological Processes. 2015;29(13):2880-2894.

16. Remondi F, Burlando P, Vollmer D. Exploring the hydrological impact of increasing urbanisation on a tropical river catchment of the metropolitan Jakarta, Indonesia. Sustainable Cities and Society. 2016;20:210-221.

17. Edward J, Menon J. Poor drain maintenance causing floods in the city. Malay Mail Online. 2017.

18. Dewan AM, Kabir MH, Nahar K, et al. Urbanisation and environmental degradation in Dhaka Metropolitan Area of Bangladesh. International Journal of Environment and Sustainable Development (IJESD). 2012;11(2):118-147.

19. Dewan TH. Societal impacts and vulnerability to floods in Bangladesh and Nepal. Weather and Climate Extremes. 2015;7:36-42.

20. Channel NewsAsia. Singapore's stormwater management strategies have “served us well”: Masagos. Channel NewsAsia. 2017.

21. Logan T. Why Bangladesh floods are so bad. BBC News. 2004.

22. Huong HT, Pathirana A. Urbanization and climate change impacts on future urban flooding in Can Tho city, Vietnam. Hydrology and Earth System Sciences. 2013;17:379-394.

23. Wasson R, Juyal N, Jaiswal M, et al. The mountain-lowland debate: Deforestation and sediment transport in the upper Ganga catchment. Journal of Environmental Management. 2008;88(1):53-61.

24. Wiekenkamp I, Huisman JA, Bogena HR, et al. Changes in measured spatiotemporal patterns of hydrological response after partial deforestation in a headwater catchment. Journal of Hydrology. 2016;542:648-661.

25. Office of Disaster Preparedness and Management. Flooding. 2013.

26. Britannica. Slash-and-burn agriculture. Encyclopaedia Britannica. 2011.

27. European Commission. Science for Environment Policy. The University of the West of England. 2015.

28. World Wide Fund. Farming: Soil erosion and degradation. 2016.

29. Astro AWANI. Terrifying images of China floods. Astro AWANI. 2013.

30. United States Environmental Protection Agency. Cooling Summertime Temperatures: Strategies to Reduce Urban Heat Islands. United States Environmental Protection Agency. 2003;1-6.

31. Dams J, Batelaan O, Nossent J, et al. A strategy towards improved hydrological model parameterisation in urbanized catchments using remote sensing derived impervious surface cover maps. ResearchGate. 2008;1-9.

32. Nagle G, Guinness P. Cambridge International A and AS Level Geography. London: Hodder Education. 2011.

33. Place for Change. (n.d.). Volunteer in the Himalayas. Place for change. 2017.

34. Bowes T. The effects of overgrazing, over- cultivation and the mismanagement of irrigated land in dryland Africa. Folio. 1998;6.

35. Pease R. Catastrophic Chinese floods triggered by air pollution. Science. 2015 .

36. Rack J. How Air Pollution May Have Caused Catastrophic Flooding In China. 2015. 